\title{
A Study on the Eccentric Loading of K Node of Steel Tube Tower
}

\author{
LIU Haifeng ${ }^{a}$ Wang Fei ${ }^{b}$ Han Junke $^{b}$ Hu XiaoGuang ${ }^{c}$ \\ China electricity power research institute, Beijing, 100055, China \\ a.liuhaifeng@epri.sgc.com.cn; b.wangfei@epri.sgc.com.cn; c.hjk@epri.sgc.com.cn; \\ d.huxiaoguang@epri.sgc.com.cn
}

Keywords: steel tube tower, negative eccentricity, bearing capacity

Abstract. At present, in the steel tube tower, all the diagonal members' axial leads intersect on the main members' axial leads which would always cause the large size of node plate. The existing theoretical analysis shows that negative eccentricity of node connection can decrease the size of node plate, reduce the windward area and improve the bearing capacity of node plate. This project will calculate the influence of negative eccentricity on the bearing capacity of node plate of steel tube tower through testing and theory. The test and theoretical analysis shows that negative eccentricity is extremely unfavorable for the overall instability of members. When the slenderness ratio is large, the negative eccentricity should be avoided, or checking calculation of bearing capacity should be carried out according to the compression-bending members, in order to avoid the overall instability failure of members, and the local buckling not occurring on the testing members, through the finite element and testing phenomenon, it is found that force-deflection curve dropped very fast at the later loading stage, which means the member bearing capacity sharply decreased and then lost stability; through the test research, it is found that the larger the negative eccentricity is, the lower the bearing capacity of main tube would be, for instance, the negative eccentricity of $3 \mathrm{D} / 8$ is $50 \%$ larger than $\mathrm{D} / 4$, but its main tube bearing capacity is about $40 \%$ lower. Therefore, the negative eccentricity is unfavorable for the overall instability bearing capacity of main tube.

\section{Introduction}

Currently in China, for the transmission steel tube tower, all the branch tubes' axial leads intersect on the main tubes' axial leads, that is to say there is no eccentricity for the intersection of branch tube and main tube ${ }^{[1-3]}$. However, at abroad, the idea of eccentric node has been introduced into the design of steel tube tower. According to the relevant theoretical analysis, the negative eccentricity connection of steel tube nodes has some advantages to some extent, such as decreasing the size of node plate and reducing the windward area, etc ${ }^{[4-5]}$. And in China, there are few theory and test researches on the eccentric connection node, let alone the type of eccentric connection of branch tube and main tube of welding neck flange node. Therefore, the project group will research the stress performance of eccentric connection node of welding neck flange and determine the influence rule on flange node and main tube bearing capacity when eccentric connection of branch tube and main tube of welding neck flange, through theoretical analysis and node test ${ }^{[6-8]}$. The research results of this project are forward-looking, which will have a certain guiding significance to the research of eccentric node of welding neck flange and other new-type nodes.

\section{Test introduction}

The $\mathrm{K}$ node, common in engineering, is selected for test, as Fig.1. The specification of main tube is $\varphi 219 \times 6$ and that of branch tube is $\varphi 133 \times 4$. The included angle of compressed branch tube and main tube takes $45^{\circ}$ and that of tensioned main tube and main tube takes $50^{\circ}$. All materials are the Q345 longitudinal welded pipes. Take $\mathrm{D} / 4$ and $3 \mathrm{D} / 8$ as the eccentricity ratio of node negative eccentricity test and $3.5 \mathrm{~m}$ as the internode length. Each group has three members. The testing specifications are listed in Table.1. 


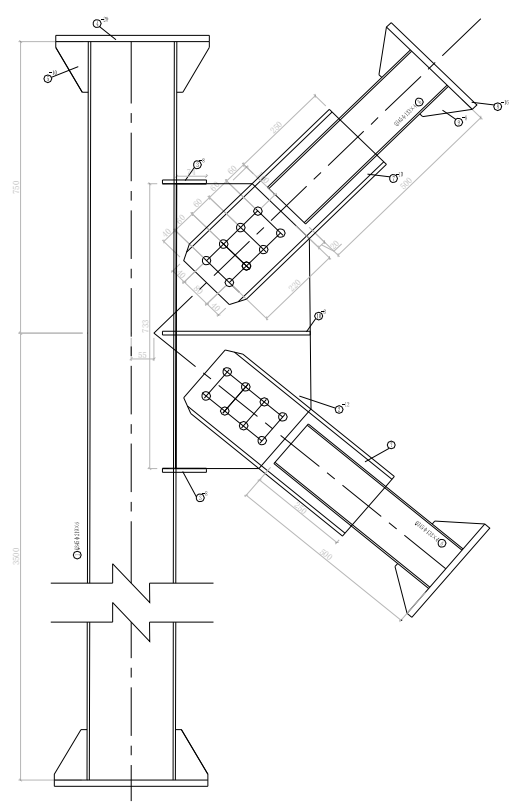

Figure.1 Schematic Diagram of Test Specimen Node Table 1 Test Sample

\begin{tabular}{|c|c|c|c|c|}
\hline Test Specimen No. & Connection Type & Thickness of Node Plate $/ \mathrm{mm}$ & Thickness of Plugboard /mm & Negative Eccentricity \\
\hline C1PC & ]-Type Plugboard & 12 & 10 & $\mathrm{D} / 4$ \\
\hline C2PC & ]-Type Plugboard & 12 & 10 & $3 \mathrm{D} / 8$ \\
\hline U3PC & U-Type Plugboard & 16 & 10 & $\mathrm{D} / 4$ \\
\hline SZX4 & Cross Plugboard & 10 & $\mathrm{D} / 4$ \\
\hline
\end{tabular}

Note: D refers to the diameter of main tube.

\section{Material Characteristic Test}

The loading of material characteristic test meets the requirements of Metal Material - Greenhouse Tensile Testing Method GB/T 228-2002. This test is mainly to investigate the ultimate bearing capacity of steel tube, so only the material characteristic test results of main tube are listed in Table 2.

Table 2 Material Characteristic Test Results

\begin{tabular}{|c|c|c|c|c|c|c|}
\hline \multicolumn{2}{|c|}{ Test Specimen No. } & $\begin{array}{c}\text { Yield Strength } \\
(\mathrm{MPa})\end{array}$ & $\begin{array}{c}\text { Tensile Strength } \\
(\mathrm{MPa})\end{array}$ & $\begin{array}{c}\text { Elasticity Modulus } \\
\left(\times 10^{5} \mathrm{~N} / \mathrm{mm}^{2}\right)\end{array}$ & $\begin{array}{c}\text { Elongation } \\
(\%)\end{array}$ & $\begin{array}{c}\text { Corresponding Test } \\
\text { Member No. }\end{array}$ \\
\hline \multirow{3}{*}{1} & C1001 & 425.70 & 555.47 & 2.003 & 37.4 & \\
\cline { 2 - 7 } & C1002 & 400.92 & 558.75 & 1.977 & 36.9 & \\
\cline { 2 - 8 } & C1003 & 408.65 & 564.81 & 2.072 & 36.0 & \\
\hline \multirow{3}{*}{2} & Mean Value & 411.76 & 559.68 & 2.017 & 36.8 & C1PC-1,C1PC-2 \\
\cline { 2 - 8 } & C1101 & 388.55 & 537.66 & 1.982 & 38.0 & \\
\cline { 2 - 8 } & C1102 & 396.62 & 548.51 & 2.042 & 38.2 & \\
\hline \multirow{3}{*}{3} & Mean Value & 390.69 & 538.72 & 1.981 & 38.2 & C1PC-3,C2PC-1 \\
\cline { 2 - 8 } & C1201 & 417.98 & 550.18 & 2.091 & 37.4 & \\
\cline { 2 - 8 } & C1202 & 411.20 & 546.28 & 1.994 & 38.5 & \\
\cline { 2 - 8 } & C1203 & 409.77 & 533.95 & 1.971 & 38.8 & \\
\hline
\end{tabular}




\section{Testing Apparatus and Loading Process}

\section{.4.1 Testing Apparatus}

The testing apparatus schematic diagram is shown in Fig.2. The bottom of test specimen is placed on the steel hinge of base, while the ends of the rest members are connected with jack.

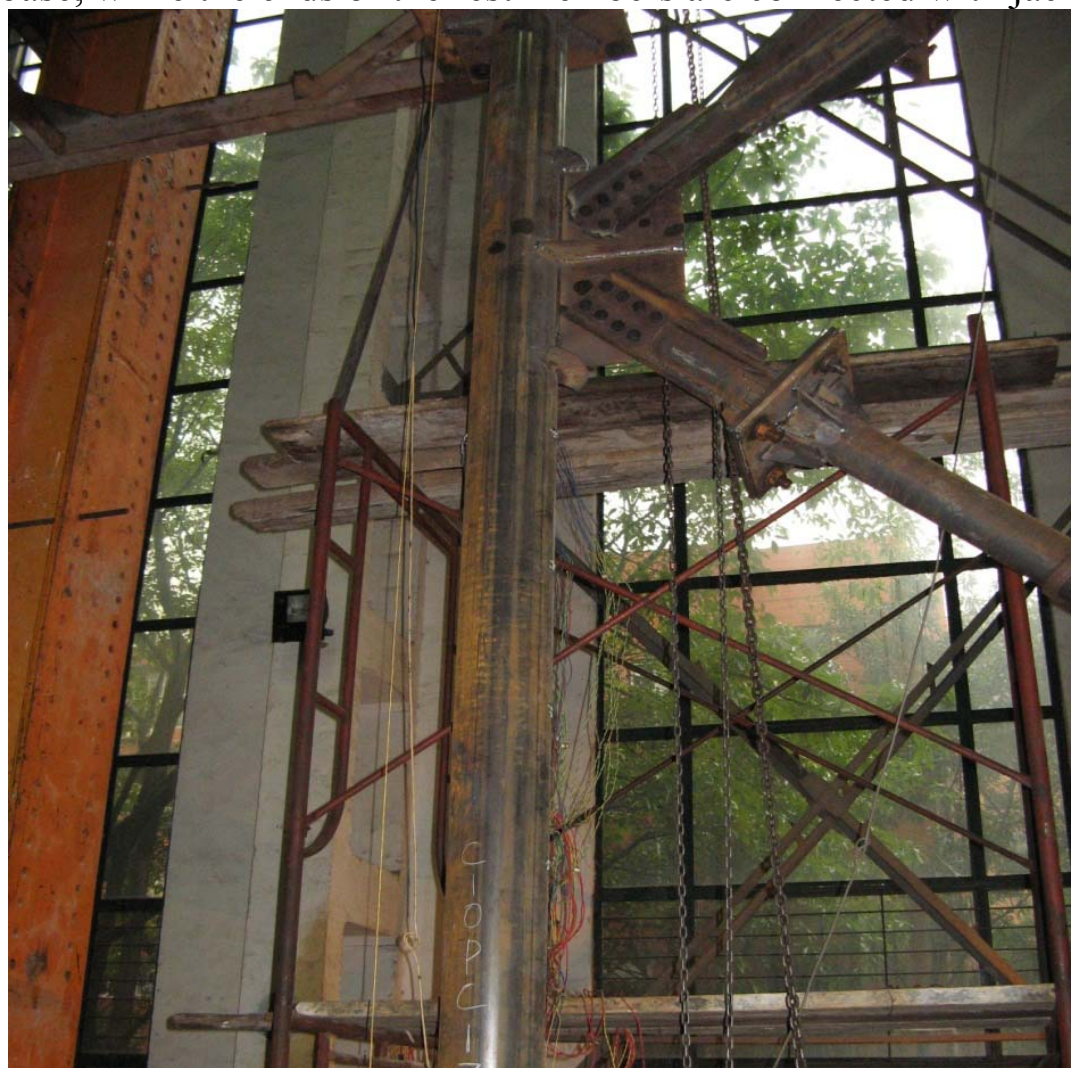

Figure.2 Field Test Loading Apparatus

\subsection{Loading Process}

Uniaxial loading is adopted for the test loading. For the branch tube bearing capacity, it should remain the same after reached a certain force value, while the loading on main tube should be progressively increased till it is destroyed. After each stage of loading, pause for 1 minute, and then continue loading up to the failure of test specimen which will cause the loading cannot be carried out any more.

\subsection{Layout of Survey Point}

In order to investigate the ultimate bearing capacity of main tube under the circumstances of different connection modes and different eccentricity ratios, the circumferential and axial strain gauges are laid out on the steel tubes to observe their stress state. One group shall be laid out on the steel tube at intervals of $30^{\circ}$. As the symmetry, only $180^{\circ}$ shall be laid out for each cross section as shown in Fig 3 : 


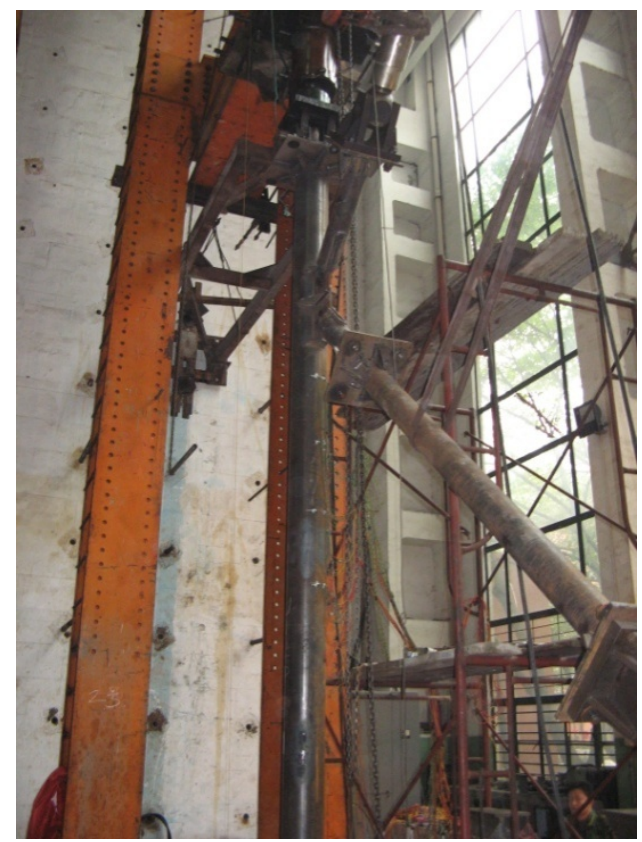

Figure.3 Strain Gauge Layout Drawing

\subsection{Test Data Processing and Test Results}

\subsubsection{Failure Characteristics of Test Specimen}

For the test and failure situation of each test specimen, please see the Figure 4.
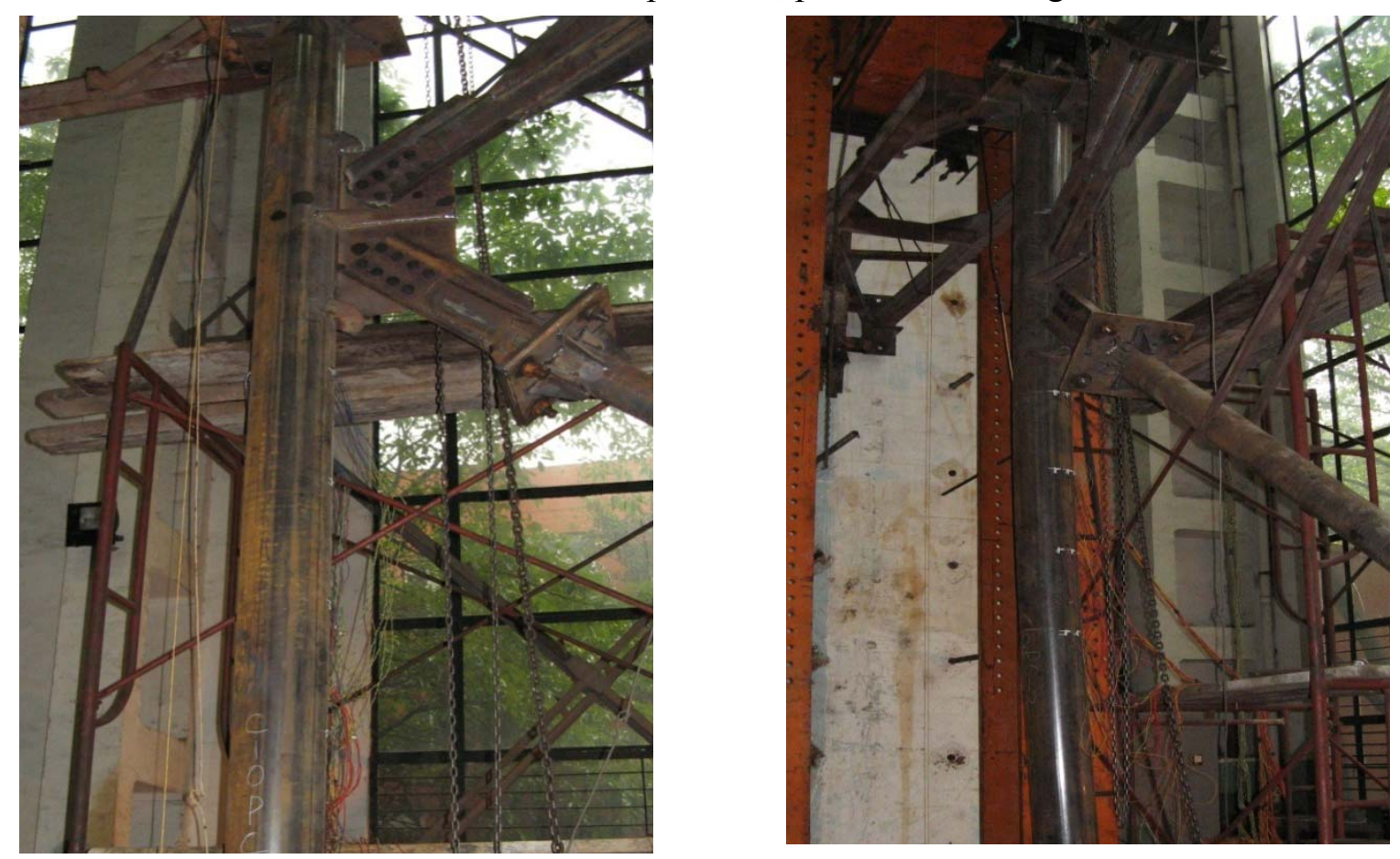

Figure.4 C1PC Failure Form

The test adopts the results of test in which the branch tube force reached the node bearing capacity. The main tube axial force and branch tube force would be simultaneously loaded in the way. When the main tube force reaches $600 \mathrm{kN} \sim 650 \mathrm{kN}$, bending occurs on the main tube, but the bending deflection is not obvious. By this time, the main tube is still able to bear a certain amount of load. Continue increasing the main tube load till the obvious deflection occurs on it. At that time, it is unable to maintain the continuous increasing trend for the force of main tube, so the main tube becomes instable. 
Most instability is in the plane of bending moment action and there is no failure of branch tube occurred at the moment of instability. While for some members, the flexure direction is in the tangential direction of additional bending moment plane when instability. As loading up to the critical load of members, they had an immediate instability, which resulted in the pressure of upper branch tube suddenly increase, and this kind of impact load also led to the failure of upper branch tube. At the time of instability of C1PC-1 test specimen, its flexure direction is in the normal direction of additional bending moment acting plane. The test phenomenon shows that major instability is in the plane of bending moment action, but subject to the secondary effect caused by additional bending moment, the relative members also may have the out-of-plane instability or the instability between the tangent and normal of additional bending moment plane. These instability forms have certain contingency.

\subsubsection{Load-Strain Curve}

In order to find out the stress distribution and the position of maximum deflection at the time that compression-bending members are instable, the load-strain curves of main tubes are prepared to judge the instability of steel tubes, so as to determine their ultimate bearing capacity.

From the test phenomenon and load-strain curves, it can be concluded that the overall instability failures of test specimens are all happened under the combined effect of pressure and bending moment. The bending stress caused by node connection negative eccentricity decreased the stability bearing capacity of main tubes which made them easier to be instable. In this test, the length of lower segment of main material is $3500 \mathrm{~mm}$, equivalently the slenderness ratio to be 46.5 .

\subsubsection{Influence of Negative Eccentricity on the Overall Bearing Capacity of Members}

According to the above load-strain curves, the ultimate bearing capacity of main tubes can be known. Combined with the acting force of branch tubes and the included angles between branch and main tubes at this time, it is able to obtain the maximum imposed load of main tubes when failure. See the Table 3:

Table 3 Test Results

\begin{tabular}{|c|c|c|c|c|c|}
\hline $\begin{array}{c}\text { Test } \\
\text { Specimen } \\
\text { No. }\end{array}$ & Eccentricity & $\begin{array}{c}\text { Ultimate Bearing } \\
\text { Capacity of Main } \\
\text { Tube }(\mathrm{kN})\end{array}$ & $\begin{array}{c}\text { Acting Force of } \\
\text { Branch Tube }(\mathrm{kN})\end{array}$ & $\begin{array}{c}\text { Maximum Load } \\
\text { on Main Tube }(\mathrm{kN})\end{array}$ & $\begin{array}{c}\text { Percentage of the Difference } \\
\text { of Axial Forces }\end{array}$ \\
\hline C1PC-1 & $\mathrm{D} / 4$ & 1180 & 300 & 1373 & $-0.52 \%$ \\
\hline $\mathrm{C} 1 \mathrm{PC}-2$ & $\mathrm{D} / 4$ & 1000 & 350 & 1225 & $-11.23 \%$ \\
\hline $\mathrm{C} 1 \mathrm{PC}-3$ & $\mathrm{D} / 4$ & 780 & 450 & 1069 & $-22.52 \%$ \\
\hline C2PC-1 & $3 \mathrm{D} / 8$ & 680 & 450 & 969 & $-29.76 \%$ \\
\hline C2PC-2 & $3 \mathrm{D} / 8$ & 700 & 450 & 989 & $-28.31 \%$ \\
\hline C2PC-3 & $3 \mathrm{D} / 8$ & 710 & 450 & 999 & $-27.59 \%$ \\
\hline
\end{tabular}

Note: The percentages of difference of axial forces in this table are subject to the value of U3PC-3 test specimen. They are the percentage of difference value between the maximum load of main tube of other members and the ultimate bearing capacity of main tube of U3PC-3.

From the maximum load on the main tube at the time of test specimen failure it can be seen that the node negative eccentricity resulted in the main tube bearing capacity decreased to different extent.

Table.3 shows that: for C1PC-1 and C1PC-2, under the same elasticity modulus E and yield strength $f_{\mathrm{y}}$ in material actual measurement, when the acting force of branch tube increased $16.67 \%$ (equivalently the increase of bending moment), the ultimate bearing capacity of main tube decreased $15.52 \%$, which means that under the same eccentricity, the larger the acting force of branch tube is, the lower the ultimate bearing capacity of main tube would be, as shown in figure 4-14.

For $\mathrm{C} 1 \mathrm{PC}-3$ and $\mathrm{C} 2 \mathrm{PC}-1$, under the same branch tube force, when the eccentricity increased 50\%, the ultimate bearing capacity of main tube decreased $12.82 \%$. So the eccentricity has greater influence on the ultimate bearing capacity of main tube. And the larger the negative eccentricity is, the lower the ultimate bearing capacity of main tube would be. For instance, the negative eccentricity 
of $\mathrm{C} 1 \mathrm{PC}$ is $\mathrm{D} / 4$ and that of $\mathrm{C} 2 \mathrm{PC}$ is $3 \mathrm{D} / 8$, but the ultimate bearing capacity of main tube of $\mathrm{C} 2 \mathrm{PC}$ decreased about $40 \%$. Therefore, the existing of negative eccentricity is extremely unfavorable for the overall instability bearing capacity of main tube.

It is important to note that: some relevant literatures, such as Woo-Bum Kim in Korea, point out that negative eccentricity is helpful to reduce the windward area and improve the bearing capacity of node. But their conclusion is based on that test specimen is just node strength, and what occurred on test specimen is local buckling failure instead of the overall failure, that is to say that node negative eccentricity is able to improve the bearing capacity of local buckling and is beneficial to the local bearing capacity of members. However, this paper researches the influence on the overall stability. For the local buckling, the finite element analysis will be made on it in the following section.

\section{Finite Element Analysis}

\subsection{Finite Element Analysis of Test Specimen}

The general finite element program ANSYS10.0 is used for the simulated analysis of nodes, so as to further understand the stress performance of nodes. This analysis adopts the solid models to simulate the node plate and steel tubes. During analysis, the branch tube force is consistent with the test situation. In the beginning, carry out simultaneous loading of branch tube and main tube axial force. Then stop loading of the branch tube force when it reaches the test design value, and keep loading of the main tube axial force till failure in Fig.5 and Table.5.

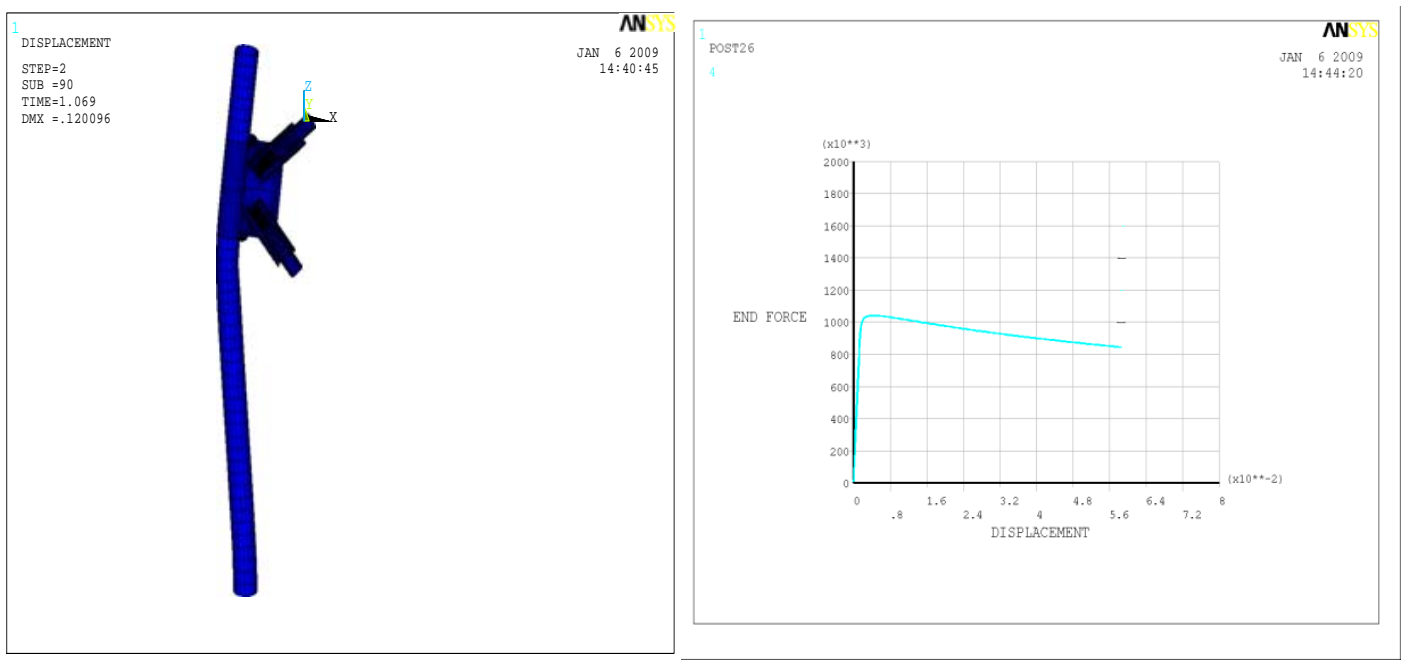

Figure.5 C1PC Member Deformation Diagram Figure 4-18 C1PC Member Load-Displacement Curve

Table 4 Comparison of the Test Result and the Finite Element Analysis Result

\begin{tabular}{|c|c|c|c|}
\hline Test Specimen & PTEST(kN) & PANSYS(kN) & PTEST/ PANSYS \\
\hline C1PC & 1000 & 1045.0 & 0.957 \\
\hline C2PC & 696.7 & 743.2 & 0.937 \\
\hline U3PC & 737.5 & 782.5 & 0.942 \\
\hline SZX4 & 693.3 & 715.8 & 0.969 \\
\hline
\end{tabular}

From the deformation process of finite element it can be seen that under the circumstance of simultaneous loading, the members are subjected to the compression-bending action and there occurs a certain deflection on main tubes. Because of the additional bending moment, the deflection is larger. Then continue to increase the main tube axial force, so that the additional bending moment is gradually increasing based on the existing deformation, which accelerates the overall instability of members. Therefore, the final failure form is comparatively consistent with the test phenomenon.

Table 4 is the comparison of the test result and the finite element analysis result. These results show that there is little difference between them, which means the finite element analysis has a relatively high reliability. 


\subsection{Finite Element Analysis of Relatively Small Slenderness Ratio}

It has been mentioned above that negative eccentricity has an influence on the structure overall instability and might be beneficial to the node local stress, that is to say, when the slenderness ratio is relatively small, the negative eccentricity of node connection can decrease the size of node plate and improve its bearing capacity. Now the analysis will be carried out through finite element as follow Fig.6.
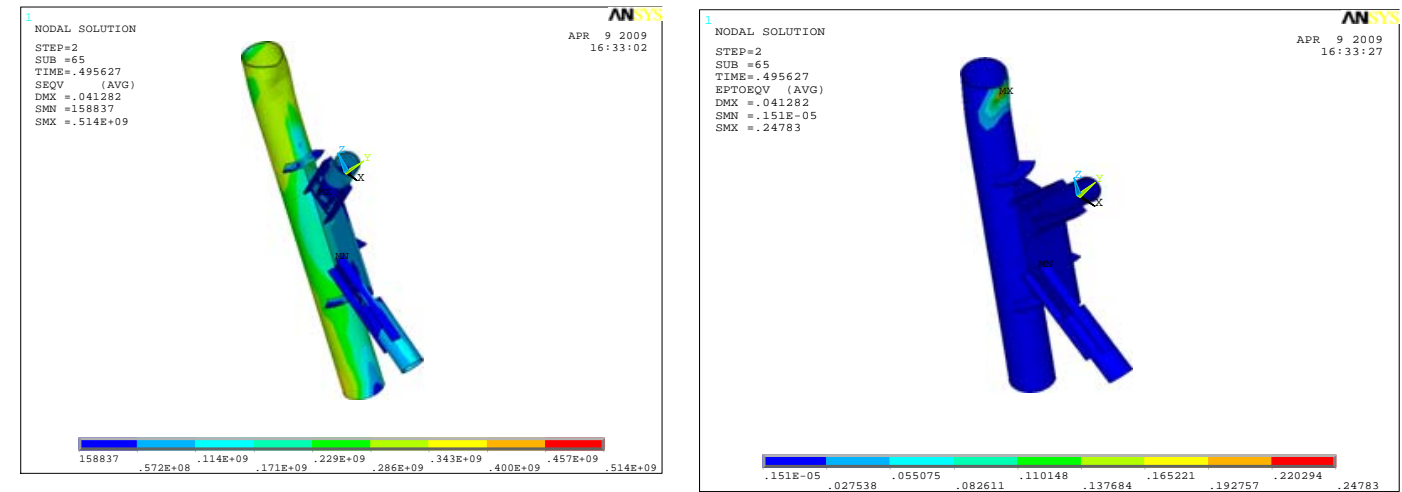

Figure.6 Stress Strain Diagram of Member U12-1

It shows that: when the slenderness ratio is relatively small, the negative eccentricity of node connection is beneficial to the members and the ultimate bearing capacity of main tube is increased, which is consistent with the result of relevant literatures.

\section{Summary}

The following conclusions can be reached from the test and the finite element analysis.

(1)The negative eccentricity is extremely unfavorable for the members' overall instability. When the slenderness ratio is relatively large, the negative eccentricity should be avoided, or checking calculation of bearing capacity should be carried out according to the compression-bending members, in order to avoid the members' overall instability failure.

(2)The local buckling didn't occur on the testing members, through the finite element and test phenomenon, it is found that force-deflection curve dropped very fast at the later loading stage, which means the member bearing capacity sharply decreased and then lost stability.

(3)Through the test research, it is found that the larger the negative eccentricity is, the lower the bearing capacity of main tube would be. For instance, the negative eccentricity of $3 \mathrm{D} / 8$ is $50 \%$ larger than $\mathrm{D} / 4$, but its main tube bearing capacity is about $40 \%$ lower. Therefore, the negative eccentricity is unfavorable for the overall instability bearing capacity of main tube.

(4)From the finite element analysis it can be seen that when the members' slenderness ratio is relatively small, the local buckling would occur prior to the overall instability, in the meantime, the negative eccentricity can increase the main tube bearing capacity and is beneficial to it. At that moment, checking calculation is not necessary.

\section{References}

[1]Yang Jianping, Li Zheng, Cheng Yongfeng, Yang Jingbo. Steel tubular tower structures of overhead transmission line[M]. Beijing: China electric power press.2011.

[2]Analysis on secondary stress of primary member of UHV transmission tower structure. Journal of Building Structures. 2012,29(4):29-32.

[3]Zhang Dian Sheng. Specification of electric engineering for ultra-high-voltage transmission line[S]. Beijing: China electric power press.2007. 
[4]LI Mao-hua, YANG Jing-bo, LI Zheng-liang, HAN Jun-ke, LI Feng. Analysis on Secondary Stress for Steel-Tube Tower of $1000 \mathrm{kV}$ Double Circuit Transmission Lines on Same Tower. Power System Technology.2010,2:20-23.

[5]BAO KAN-YUAN. SHEN GUO-HUI. SUN BINGNAN, et ai. Experimental study and theoretical analysisof ultimate strength for steel tubular $\mathrm{K}$ - joint of talltowers[J]. Engineering Mechanics, 2008, 25(12): 114-122.

[6]ELCHALAKANI M , ZHAO X L, GRZEBIETA R H. Plastic mechanism analysis of circular tubes under purebending [J]. International Journal of MechanicalSciences, Elsevier, 2006, 44(6): $1117-1143$

[7]GUO J1AN, SUN BIN( 、 rNAN. The whole courseanalysis of failure behavior of tube - gusset joint in steeltubular tower[J]. Industrial Construction, 2006, 36(12): 83-86.

[8]awada Y, ldogaki S, Sketia K. Static and fatigue testson T-joints stiffened by al internal ring[C] / / Proceedings of Ofshore Technology Conference. Houston, Tex—as. USA. 1979: 563—574. 